\title{
EDUCAR PARA A LIBERDADE EM KANT: REFLEXÕES ACERCA DO PROJETO PEDAGÓGICO NA MODERNIDADE
}

\section{ENSAIO TEÓRICO}

SANTOS, Willian Lima ${ }^{1}$

SANTOS, Willian Lima. Educar para a liberdade em Kant: Reflexões acerca do projeto pedagógico na modernidade. Revista Científica Multidisciplinar Núcleo do Conhecimento. Ano 05, Ed. 05, Vol. 04, pp. 104-110. Maio de 2020. ISSN: 2448-0959, Link de acesso: https://www.nucleodoconhecimento.com.br/educacao/liberdade-emkant

\section{RESUMO}

O presente ensaio foi desenvolvido na disciplina de Fundamentos da Educação I, no curso de Mestrado Acadêmico em Educação da Universidade Federal de Sergipe (UFS), tendo como principal objetivo refletir sobre o modelo pedagógico kantiano na modernidade, traçando um elo entre disciplina, instrução e formação para a liberdade. Trata-se de um estudo bibliográfico, construído a partir do seguinte quadro teórico: Kant (1996), Menezes (1992), Menezes (2005), Menezes e Boto (2014). Diante das análises do material bibliográfico foi possível perceber que 0 ato de educar com disciplina em Kant é tirar o homem de seu estado bruto, eliminando a barbárie de sua essência, para que a sua animalidade não prejudique a formação do caráter, e consequentemente a sociedade.

Palavras-chave: Kant, educação, disciplina, instrução, liberdade.

\footnotetext{
${ }^{1}$ Mestrando em Educação pelo Programa de Pós-Graduação em Educação da Universidade Federal de Sergipe (PPGED/UFS). Especialista em Tecnologias e Educação Aberta e Digital pela Universidade Federal do Recôncavo da Bahia (UFRB). Licenciado em Pedagogia pela Faculdade do Nordeste da Bahia (FANEB).
} 


\section{INTRODUÇÃO}

Considerado um dos maiores pensadores do período moderno da Filosofia, Immanuel Kant, filósofo alemão do século XVIII, abordou questões relevantes que abrangiam desde os campos educacionais, sociais e políticos, até os campos de natureza lógica e científica. Neste estudo focaremos apenas nos aspectos educacionais oriundos a partir de Kant em sua obra Sobre a Pedagogia.

Compreender o projeto pedagógico da Modernidade, numa perspectiva kantiana, nos faz refletir sobre problemas educacionais que atravessaram séculos, e que em plena contemporaneidade ainda não foram solucionados. Como por exemplo: a questão da indisciplina, assim como questionamentos acerca da razão e moralidade.

A escolha desta temática se justifica pela ausência de estudos teóricos, oriundos da Modernidade Filosófica, nos cursos de formação inicial de professores. Considerando que dentro deste período ocorreram grandes transformações para o campo da educação, tratado neste estudo a partir de Kant.

Sobre o período da Modernidade é preciso considerar que não há uma medida específica para o seu início, estudos datados por diversos pesquisadores revelam que este período ocorreu entre os séculos XVI e XVIII, este último é concebido como o século da Pedagogia. De modo geral, a educação moderna se contrapõe ao modelo pedagógico medieval, para afirmar a necessidade de uma educação que prepare o indivíduo para a cidadania (via formação de um sujeito).

\section{KANT: EDUCAR PARA A LIBERDADE}

Antes de aprofundarmos nesse tema, é preciso destacar a influência da Igreja e da religião para a conduta humana, algo significativamente presente na história, como no mundo antigo, perpassando pela modernidade, e que prevalece na contemporaneidade. O homem sempre esteve em busca de respostas, e encontrava conforto para suas indagações no divino, ou seja, através da fé. Mas a religião não dava conta de explicar todos os fatos. Immanuel Kant, como filósofo da modernidade, 
primava entre suas ideais, à razão como ponto primordial. Sendo assim, é necessário compreendermos e separarmos as três esferas: verdades da fé (religião), verdade de fato (ciência) e verdades da razão (filosofia). Aqui podemos destacar também, de forma resumida, alguns fatos e personagens históricos que influenciaram a formação da conduta humana, cada um em seu tempo. O primeiro nome que se pode mencionar é o de Santo Agostinho, um dos primeiros grandes teóricos do cristianismo, que acreditava que o tempo era linear, sendo uma distinção da alma, seu ideal era totalmente voltado para o indivíduo, já que a salvação é individual, seja pelas boas ações ou por compra de indulgências. Segundo ele, ser livre no mundo do pecado é uma ilusão.

A partir da Reforma Protestante ocorreu o primeiro grande embate para a Igreja Católica, vindo à tona a questão da materialidade da fé e o questionamento sobre o poder autoritário da Igreja. Martin Lutero, que era um monge agostiniano, escreveu 95 teses contra a Igreja católica, provocado pelo problema das indulgências, para ele o cristão para ser livre em Deus não precisaria de obras, e sim ter fé nas palavras sagradas (o divino está na consciência); não obstante, a Revolução Galilaica também trouxera à tona questões sobre o método e a produção de conhecimento, além da separação do que seria as verdades de fato (ciência) das verdades de fé (religião). Entretanto, a moral kantiana não aceita a ideia de que a religião forma a consciência. A razão seria o fruto disciplina, da instrução com formação, e é nessa perspectiva que convém ressaltar que para este filósofo da modernidade educar "é converter o animal em homem, e ser homem, é ser o legislador de suas ações sob o primado da razão" (MENEZES, 2005, p.19).

O Projeto Pedagógico Moderno (século XVIII) surge a partir da necessidade de levar o indivíduo a pensar por si mesmo, conhecer a si mesmo e se autonomizar, almejando uma preparação que parte do individual para o coletivo, ou seja, preparação para integrar o meio social, em outras palavras, a formação do cidadão. Mas esse processo não ocorre de modo extintivo ou natural, considerando que é um processo que demanda disciplina e instrução, para que se chegue à formação (cidadã). 
Logo, tratar da disciplina e liberdade no modelo pedagógico Kantiano faz-nos pensar sobre a ideia da maioridade, considerando que é necessário que o indivíduo amadureça para fazer bom uso da razão, e assim buscar sua autonomia do pensamento. Sendo assim, educar o homem na perspectiva da modernidade é conduzi-lo para acertar, já o erro seria considerado o mau emprego da razão. E em Kant (1996, p.442), é perceptível que "o homem tem necessidade de sua própria razão. Não tem instinto, e precisa formar por si mesmo o projeto de sua conduta".

Segundo o filósofo alemão, a educação é o que transforma o aspecto bárbaro em aspecto humano, considerando também que o homem é o único ser que precisa ser educado, mas é a disciplina que prepara o indivíduo para a moral e para fazer o bom uso de sua liberdade. Entretanto, observa-se que o processo educacional apresenta aspectos negativos e positivos, sendo o cuidado e a disciplina o negativo, ao fazer uso do impedimento e do constrangimento para sair da barbárie, já a instrução e a formação apresentam aspecto positivo, pois o foco inicial está centrado na formação do ser disciplinado, impedindo assim que os manifestos de animalidade interfiram na formação do caráter, seja no individual ou na coletividade; já na instrução acrescentam-se os conteúdos, orientações, e direcionamento segundo as leis (regras).

Sobre a disciplina, Kant (1996, p.12) ressalta que:

[...] é o que impede ao homem de desviar-se do seu destino, de desviarse da humanidade, através de suas inclinações animais. Ela deve, por exemplo, conte-lo, de modo que não se lance ao perigo como um animal feroz, ou como um estupido. Mas, a disciplina é puramente negativa, porque é o tratamento através do qual se tirado homem sua selvageria; a instrução, pelo contrário, é a parte positiva da educação.

A educação moderna, de modo significativo, contrapõe-se ao modelo pedagógico medieval (autoritário, com uso do latim, e rigorosamente religioso), para afirmar a necessidade de uma educação que possa preparar o homem para a cidadania (formação do sujeito). Em Kant, a educação possibilita disciplinar o homem, sendo 
essencial para que ele faça uso consciente de sua liberdade. Disciplinar-se em Kant requer fazer o uso racional do pensamento em busca dessa tão sonhada liberdade. Educar é uma condição necessária para que o homem alcance autonomia, e essa conceituação de indivíduo autônomo é o que conduz a liberdade. Ele designa liberdade como autonomia, ou simplesmente a propriedade dos seres racionais de legislarem para si próprios.

Essa educação para a liberdade precisa ser exercitada, e necessita e ensinamentos para permitir o desenvolvimento da inteligência do homem. Considerando que, por ser racional, vai além de uma ordenação mecânica de sua existência, ocasionando em si próprio a libertação dos instintos por meio de sua razão.

A disciplina é peça fundamental para o uso da liberdade, logo, ela exerce relevante papel para a moralização e compreensão do que é bom ou mau. A questão da disciplina e do constrangimento é para que o indivíduo saiba usar bem a sua liberdade, de modo que a sua liberdade não ouse ferir a liberdade de outros. Nessa perspectiva, faz-se necessário ao homem assumir sua condição de ser pensante (racional) e livre, atingindo o estado de esclarecimento, que é a sua saída da menoridade, ou seja, a saída da fase em que o homem é incapaz de fazer uso do seu próprio entendimento sem a direção de outrem.

O homem por si só não desenvolveria a própria razão, pois não tem instintos, vem ao mundo num estado bruto, e depende do auxílio e cuidado de outros. Como destaca Kant (1996) a espécie humana é obrigada a extrair de si mesma pouco a pouco, com suas próprias forças, todas as qualidades naturais, que pertencem à humanidade. Uma geração educa a outra. Em sua obra Sobre a Pedagogia, Kant divide a formação educacional na modernidade em três períodos distintos que norteiam o desenvolvimento do homem: física, intelectual e moral.

O primeiro passo desse Projeto Pedagógico foi entender a noção de "criança" como ser que necessita de cuidados (precaução e tratos), não é um adulto em miniatura, e que se faz necessário respeitar o seu tempo de desenvolvimento. No texto, entendese como precaução o olhar cauteloso dos pais para impedir que a criança 
inocentemente faça uso de suas próprias forças contra si mesmo. Como até certa idade a razão não se manifesta na criança, é preciso focar no corpo e não ir diretamente para o espírito. Surge então a Educação Física, que por sua vez, está subordinada ao projeto pedagógico a este projeto pedagógico, preparando o corpo que naquele momento ainda não está apto para a racionalidade. Sobre a educação física, Menezes (1992, p.463) ressalta que:

A educação física subdivide-se em duas: educação do corpo propriamente dita - que consiste nos cuidados iniciais ofertados pelos parentes, amas etc, e deve ser negativa -, e a educação física intensa o corpo não é somente conservado, ele é exercitado [...]

Segundo Kant, a primeira educação deve somente ser negativa, ou seja, nada se deve acrescentar, esta fase objetiva apenas para além das precauções, impedir com que as crianças se tornem frágeis, ou seja, objetiva tornar resistente à criança. O segundo momento da educação física, diz respeito ao exercício do corpo, o desenvolvimento dos órgãos do sentido e dos movimentos voluntários, com práticas corporais, jogos, e a ginástica. Kant enfatiza que a parte positiva da educação física é a cultura, sendo considerada uma característica marcante que distingue o homem dos animais, além de se basear no exercício das faculdades mentais. E nessa perspectiva o filósofo moderno define que "quem não tem cultura é um bruto; quem não tem disciplina ou educação é um selvagem" (KANT, 1996, p.16).

Já a educação intelectual, dever da escola, tem a finalidade de formar os aspectos culturais no sujeito, e nessa fase Kant distingue dois tipos de cultura: a física do espírito e a moral. A primeira está voltada para a natureza, já a outra para a liberdade. O homem pode ter sido bem preservado, ter sido bem instruído, e mesmo assim desviar-se do seu destino no cultivo de sua moralidade tornando-se um homem ruim. E quando falamos em moralidade, de acordo com Menezes e Boto (2014) não é das ações visíveis que estamos tratando, mas dos seus princípios íntimos. No tocante a distinção dos dois tipos de culturas mencionados por Kant, a cultura livre que é algo mais simples, com ênfase na ludicidade e o divertimento da criança, enquanto a cultura escolar é concebida como algo sério, que exerce o constrangimento, o 
controle, a instrução, e é essa cultura que traz a essência de trabalho para a criança, e que lugar melhor para exercitar e naturalizar o exercício do trabalho do que na escola?

A culminância do projeto educacional em Kant é a moralidade, e é nesse sentido que o trabalho prepara a criança para a educação moral. A educação moral, por sua vez, traz em sua completude o desenvolvimento de todas as fases anteriores da educação (educação física e a intelectual).

A criança sendo habituada a trabalhar por constrangimento na escola, está submissa a uma obediência passiva, absoluta, para falar como Kant, mas da qual o resultado é uma atividade do próprio infante. Assim, a disciplina interioriza e pouco a pouco a criança passa a obedecer a si mesma descobrindo a liberdade. A obediência transformou-se em obediência voluntária, isto é, não mais fundada sob a autoridade de outro, mas uma obediência que primeiramente atende a razão, obediência a si mesmo, autonomia [...] (MENEZES, 1992, p.471).

A educação escolar faz parte da cultura obrigatória, e desde cedo é importante que a criança seja disciplinada para o trabalho. O papel da escola neste cenário é fazer com que as crianças se habituem a permanecerem sentadas e obedecerem tudo aquilo que thes é mandado, para que assim quando adultas elas não sigam a risca os próprios caprichos. O não reconhecimento da lei e das regras é um estado bruto de selvageria. Também é válido reforçar a existência de regras para todas as ações que podem cultivar o entendimento, ultrapassando a parte mecânica, ou seja, que o homem tenha consciência diante da regra que está seguindo. Ainda na educação da criança, Kant enfatiza a necessidade de educar a criança não apenas para o presente, mas para os caminhos que norteiam o futuro da humanidade, as progressões e mudanças que podem vir a ocorrer.

O esclarecimento, por sua vez, exige liberdade. A autonomia do pensamento é uma das maiores evoluções do ser humano; é o que nos traz a independência como seres racionais únicos e diferentes (dentro da própria espécie), têm interiorizada a 
moralidade que foi desenvolvida ao longo da formação para a liberdade (educação para a cidadania) que recebemos não muito diferente do modelo pedagógico kantiano, entretanto, racionalmente precisamos estar atentos para o uso da autoconsciência, e para isso se faz necessário que tenhamos o esclarecimento.

\section{CONCLUSÃO}

De modo geral, observamos no projeto pedagógico kantiano uma objetividade para a formação do cidadão, portanto, através da educação em Kant, o homem precisa ser disciplinado para que a animalidade não prejudique seu caráter e a sociedade. Precisa tornar-se culto, a cultura abrange a instrução e vários conhecimentos. O homem não é nada além daquilo que a educação pode fazer dele. E para isso necessita desenvolver a civilidade, isto é, modos corteses, gentileza e prudência para ser querido em sociedade e possa desempenhar influência nela; e para, além disso, precisa ter uma boa disposição para escolher apenas os bons fins (fazendo bom uso de sua liberdade).

Fazendo bom uso da liberdade, o homem não atentará contra a liberdade de outros, só assim indivíduo estaria pronto para a cidadania e para vida em sociedade. Kant, em sua obra Sobre a Pedagogia, apresentou aspectos significativos sobre a natureza do homem ao vir ao mundo (bárbaro), e como o ser pode ser transformado através da educação. A educação para este filósofo é a fonte de onde brota todo o bem neste mundo, e o homem como ser racional depende dela para alcançar a plenitude de seu destino.

É possível estabelecer de forma direta uma relação entre filosofia educacional kantiana e a educação brasileira, considerando que a legislação em vigor no país frisa por educar o aluno apoiando-se em dois princípios fundamentais o exercício e a prática da cidadania e o exercício e a prática do trabalho. 


\section{REFERÊNCIAS}

KANT, Immanuel. Sobre a Pedagogia. Trad. Francisco Cock Fontanella. Piracicaba: Editora UNIMEP, 1996.

MENEZES, Edmilson. Kant e a Pedagogia. Educação \& Sociedade: Revista quadrimestral de Ciência e Educação / Centro de Estudos de Educação e Sociedade (CEDES), n43, 1992.

MENEZES, Edmilson. Kant e a concepção moderna de uma Educação para o corpo. In: NASCIMENTO, Jorge Carvalho do (org.). Problemas de educação escolar e extra-escolar. São Cristóvão: Editora UFS, 2005.

MENEZES, Edmilson; BOTO, Carlota. Algumas notas sobre educação e ética à luz do pensamento de Kant. In: Educação (Porto Alegre, impresso), v. 37, n. 3, p. 441453, set.-dez, 2014.

Enviado: Janeiro, 2020.

Aprovado: Maio, 2020. 